\title{
Seasonality and total 25-hydroxyvitamin D levels as sources of potential misclassification of vitamin $D$ deficiency
}

To the Editor -

The Western Australian Pregnancy (Raine) cohort that measured serum 25-hydroxyvitamin D levels from a subset of mothers from a longitudinal community-based study ( $n=929)$, has provided Zosky and colleagues with the unique opportunity to examine relationships between prenatal vitamin $D$ deficiency, asthma and reductions in lung function for offspring when they were six and fourteen years old (1). The main findings included a modest reduction in FVC in a combined analysis of sixyear-old boys and girls, in association with an increased asthma association for boys, neither of which were evident at age 14 . As the authors measured total 25-hydroxyvitamin D levels and did not take seasonal variation into account, residual confounding might have contributed to the earlier findings.

Exposure to UV-B radiation provides the main source of vitamin D, so circulating levels can decrease with lesser sun exposure in the absence of supplementation, particularly in regions of maximum latitude. For South Florida which is usually warm and sunny all year-round (latitude $25.46^{\circ} \mathrm{N}$ ), compared with levels measured in winter, serum 25-hydroxyvitamin D levels during the summer months were still significantly increased by $14.8 \%$ and $13 \%$ for participating men and women respectively (2). As Perth in Western Australia is at a latitude of $31.95^{\circ} \mathrm{S}$, even greater variations in seasonal levels might be expected with the potential to misclassify cases of maternal vitamin $D$ deficiency.

The Avon Longitudinal Study of Parents and Children (ALSPAC) that prospectively measured 25hydroxyvitamin D levels from a subset of at least 7,700 pregnant women of the South West of England, found seasonal effects with regard to lung function outcomes for offspring with a mean age of 8.7 years (3). Reductions in the minimally adjusted mean difference for $\mathrm{FEV}_{1}$ and FVC were observed for the lowest as compared with the highest quintile of 25 -hydroxyvitamin $D$, however, no differences remained after adjusting for seasonality. The adjustment did not change the null result for asthma.

In addition, it is now appreciated that estimated levels of bioavailable 25-hydroxyvitamin D may be more appropriate than the total level, at least with regard to bone homeostasis. Between $85 \%$ and $90 \%$ of the total 25 -hydroxyvitamin $D$ is bound to vitamin D-binding protein, in contrast to the lesser but more functional 'non-vitamin D-binding protein fraction' (4). Compared with white Americans, black Americans were estimated to have similar concentrations of this bioavailable fraction as well as greater bone mineral density, in spite of lower total and correspondingly lower vitamin D-binding protein levels that might be largely explained by two genetic polymorphisms. Though ethnicityrelated data for native-born and migrant Australians are not yet available, a description of the ethnic mix of the Raine study participants might have been informative. This bioavailable form which is likely to have a genetic basis and unlikely to be proportionally related to total levels (4), raises the possibility of measurement error and a further source of misclassification of exposure categories. Bioavailable 25-hydroxyvitamin $D$ is distinct from the biologically active form, 1,25-dihydroxyvitamin $D$, and the influence of the latter with regard to the bioavailable form and mineral metabolism has not yet been established (4). A possible benefit of using the active metabolite over total 25- 
hydroxyvitamin D levels was acknowledged by the authors.

Adopting the use of bioavailable 25-hydroxyvitamin D levels with seasonal adjustment as the exposure may prove advantageous when examining for the lung health effects of prenatal vitamin $D$ deficiency. The inconsistencies of the current literature may relate in part to the variation of definitions for total 25 -hydroxyvitamin $D$ deficiency and variable inclusion of seasonality as a confounder (5), through its influence on the estimated strengths of association for asthma and lung function outcomes.

Words $=599$

\section{REFERENCES}

1. Zosky GR, Hart PH, Whitehouse AJ, Kusel MM, Ang W, Foong RE, Chen L, Holt PG, Sly PD, Hall GL. Vitamin D deficiency at 16 to 20 weeks' gestation is associated with impaired lung function and asthma at 6 years of age. Annals of the American Thoracic Society 2014;11:571-577.

2. Levis S, Gomez A, Jimenez C, Veras L, Ma F, Lai S, Hollis B, Roos BA. Vitamin D deficiency and seasonal variation in an adult South Florida population. J Clin Endocrinol Metab 2005;90:1557-1562.

3. Wills AK, Shaheen SO, Granell R, Henderson AJ, Fraser WD, Lawlor DA. Maternal 25hydroxyvitamin $\mathrm{D}$ and its association with childhood atopic outcomes and lung function. Clin Exp Allergy 2013;43:1180-1188.

4. Powe CE, Evans MK, Wenger J, Zonderman AB, Berg AH, Nalls M, Tamez H, Zhang D, Bhan I, Karumanchi SA, Powe NR, Thadhani R. Vitamin D-binding protein and vitamin D status of black Americans and white Americans. N Engl J Med 2013;369:1991-2000.

5. Sokol SI, Tsang P, Aggarwal V, Melamed ML, Srinivas VS. Vitamin D status and risk of cardiovascular events: Lessons learned via systematic review and meta-analysis. Cardiology in review 2011;19:192-201. 